\title{
Temporal variation of wind speed and wind direction and interrelationship between air temperature and wind speed for different climatic seasons Northern State, Sudan
}

\begin{abstract}
The research aims to study the temporal variability of wind speed and direction and their correlation with air temperature in different climatic seasons in Northern State, to produce broad data base on winds variability and interrelationship between air temperature and wind speed for different climatic seasons. Mean monthly and daily climatic data dating back to 2001(first season) and 2011(second season) were obtained from Karima meteorological station representing three different climatic seasons namely: April for summer, August for autumn and December for winter. Data were subjected to simple regression analysis, statistical analysis and computations were done by "Excel 2000". The results showed that the wind speed varied widely during each month and day even within the same climatic season. In two seasons, the diurnal variation for different climatic seasons Apr., Aug. and Dec. was much lower than the monthly; due to the higher monthly variability of wind speed. The results also revealed that the prevailing direction of winds was generally northwards. The results of April in the first season are presented as an example; the mean daily wind speed (Va) ranged from 0.6 to $17 \mathrm{~m} / \mathrm{s}$, with a mean of $7.2 \mathrm{~m} / \mathrm{s}$, a STD of 4.3 and a CV of $60 \%$. The daily mean data ranged from $5.4(3 \mathrm{hrs})$ to $8.2(24 \mathrm{hrs})$, with a mean of $7.2 \mathrm{~m} / \mathrm{s}$, a STD of 1.1 and a CV of $15.3 \%$.The prevailing wind direction decreases in the following order: $\mathrm{N}>\mathrm{NE}=\mathrm{NNE}>\mathrm{NNW}$. The monthly variability of the air temperature in the two seasons decreased in the following order: winter $>$ summer $>$ autumn. Significant, inversely proportional and cubic wind speed-temperature correlations in the two seasons for Aug. and Dec. were $(\mathrm{P}<0.05, \mathrm{r}=0.362) ;(\mathrm{P}<0.01, \mathrm{r}=0.488) ;(\mathrm{P}<0.001, \mathrm{R}=585)$ and $(\mathrm{P}<0.001, \mathrm{r}=$ $0.679)$, respectively.
\end{abstract}

Keywords: climatic season, regression analysis, inversely proportional and Sudan
Volume 6 Issue 4 - 202I

\author{
Mohammed Ahmed Haj Alzubair,' Motasim \\ Hyder Abdelwahab ${ }^{2}$ \\ 'Associate Professor, Physical geography, University of \\ Khartoum, Sudan \\ ${ }^{2}$ Associate Professor, Faculty of Agriculture, Omdurman Islamic \\ University, Sudan
}

Correspondence: Mohammed Ahmed Haj Alzubair, Associate Professor, Physical geography, University of Khartoum, Sudan, Email abozaker68@gmail.com

Received: July 09, 2021 | Published: August 13, 2021

\section{Introduction}

Humanity has always had an interest in weather patterns. In the last century and a half, wider implications of global temperature and trends and how they might impact the planet, wildlife and humanity have become more studied. Environmental science is the study of the effects of natural and unnatural processes, and of interactions of the physical components of the planet on the environment (particularly human action). Environmental Science covers a number of disciplines: climatology, oceanography, atmospheric sciences, meteorology, and ecology. It also covers, while having much in common with biology, physics, geology and a lot of other older disciplines. Climate Change is studied under the modern discipline of Environmental Science, which is a branch of Earth Sciences or Atmospheric Sciences and crosses many boundaries, incorporating a wide variety of methods and tools. Climate variability has direct influences or many sectors such as our life especially in urban areas due to human comfort and health beside the agricultural sector. High air temperature and below normal precipitation can cause moisture stress to agricultural crops, such as corn and soybeans, and has negative impact on yields. ${ }^{1}$ Air temperature variation brings change in water evaporation and air saturation, leading to change in air humidity. Furthermore, air temperature differences between different locations will also cause air pressure differences, which in turn would produce air movement, thereby leading to wind. This variation in humidity and wind speed and direction affects rainfall. Thus, all weather variables on the Earth are more or less affected by each other and this fact is widely acknowledged. ${ }^{1-5}$ Some attempts were done in this field: Kittaka and Miyazaki ${ }^{6}$ studied the relationship between wind direction and air temperature in the Osaka center city determined using fixed point observation. They found that air temperature differences on the river side area were lower when the wind blew from the west and that air temperature differences were higher when the wind blew from the north to the east. Air temperature differences in the business districts were higher than air temperature difference, in other areas and that the influence of wind direction was not clear in these areas. Abdelwahab and Mustafa $^{7}$ assessed the monthly and diurnal variation of wind speed and direction and wind erosivity in the River Nile State. They found that winds and erosive winds (velocity $>5.4 \mathrm{~m} / \mathrm{sec}$ ) varied widely in direction and speed during each month and day even within the same climatic season. The results also showed that erosive winds ranged from 0 (Nov., 2008) to 369.8 (Feb., 2009) with a mean of $255.1(\mathrm{~m} / \mathrm{s})^{3}$, and a CV of $43.6 \%$. The wind pressure of the erosive winds ranged from 0 (Nov., 2008) to 27.1 (Jan., 2009) with a mean of 
$21.1\left(\mathrm{Nm}^{-2}\right)$ and a CV of $42.1 \%$. The trend of the monthly variation of wind pressure was qualitatively similar to that of wind erosivity (Wr). Adam and Abdalla, ${ }^{8}$ studied the climate of the drylands in Sudan; they found that deforestation affects the effective rainfall but not the actual rainfall. Climate change is a reality and unless serious efforts are made to stop increases in $\mathrm{CO}_{2}$, global temperature will continue to rise. Increase in temperature will lead to an increase in water vapour in the atmosphere and that the estimated increase in energy as a result of an increase of $0.1^{\circ} \mathrm{C}$ is about 7000 billion mega joules. This energy has to be dissipated in the form of more frequent and more intense storms leading to more floods and destructive winds. ${ }^{9}$ Mohamed and Mohamed ${ }^{10}$ made classification of climates of Sudan using aridity indices. They classified the climate of Sudan into hyper-arid, arid, semi-arid, sub-humid and humid zones. Mohamed ${ }^{11}$ made a simple thermal zonation of the Sudan; he found that Sudan can be divided into seven zones according to mean annual temperatures. He found that Khartoum and Atbara had the highest means and El-fashir and Wadihalfa had the lowest one (Figure 1).

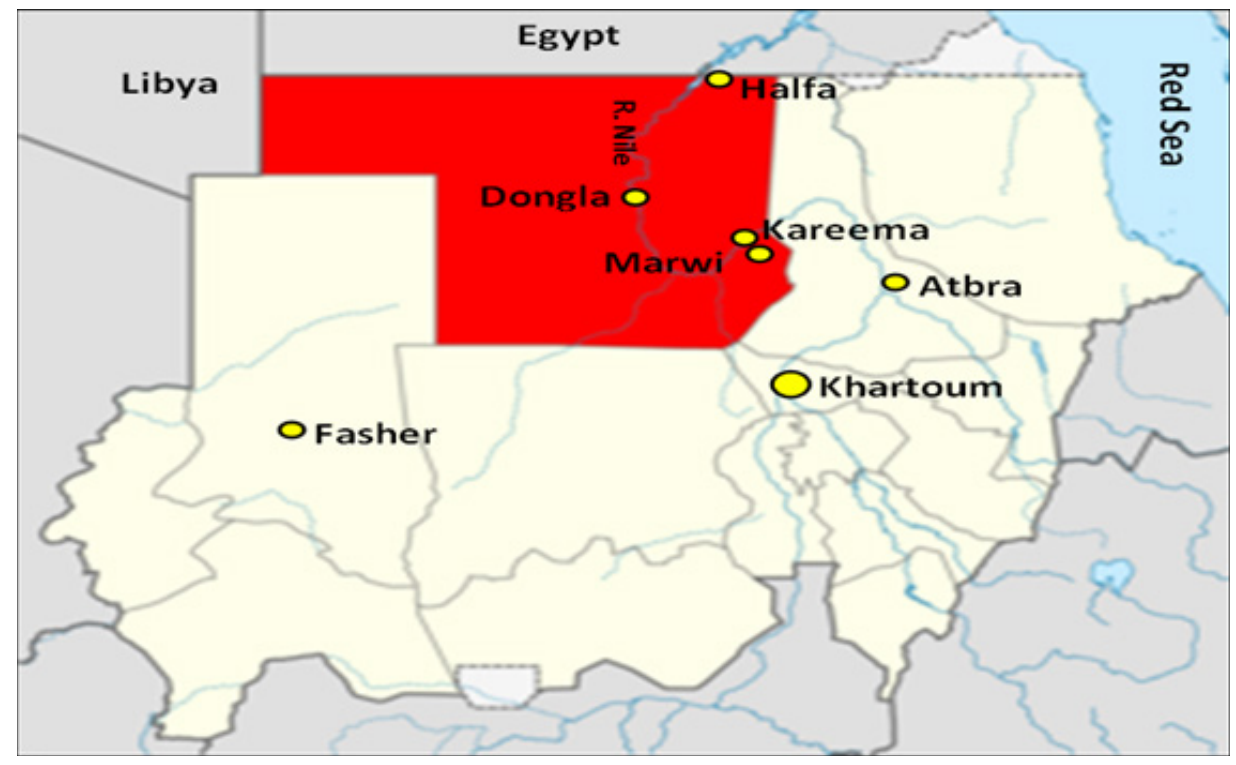

Figure I Northern State location in the Sudan.

Abuzied ${ }^{12}$ assessed and mapped wind erosion in the Northern State. He found that the winds that caused the greatest sand movement were the north and north east winds blowing from October to May and being worst from February to May. The amount of sand encroachment to the River Nile was $45.5 \mathrm{~m}^{3} / \mathrm{km}$-width/day. Agroclimatology is an applied science that is concerned with the relationships be tween weather and agricultural production. So the knowledge and analyzing meteorological data is essential for crop production that existing on all scales of space and time. i.e., mico, local, regional and global. Application of agroclimatology becomes more useful for understanding the dynarnics of agricultural production as a function of weather and climate are better understood.

Generation of analyzing meteorological data is essential for designing wind erosion control methods, particularly in arid lands. Furthermore in Sudan, till now very little attention was paid to meteorological data analysis, so it is necessary to carry out studies in all climate elements particularly winds in arid lands to avoid its negative impacts on all live kinds. The present study was undertaken to achieve the following objectives:

a. To generate broad-base quantitative data on wind speed, wind direction and interrelationship between air temperature and wind speed in the Northern State that may help in designing wind erosion control projects.

b. To investigate monthly and diurnal variation of wind speed and wind direction within different climatic seasons. c. To explore the kind of interrelationship between air temperature and wind speed in three different climatic seasons.

\section{Materials and methods}

\section{The study area}

The study was undertaken at Karima area, which is part of the Northern State lies between latitudes $17^{\circ} 45-19^{\circ} 15^{\prime} \mathrm{N}$ and longitude $30^{\circ} 15^{\prime}-32^{\circ} 00^{\prime} \mathrm{E}$. There are three meteorological stations in Northern state, located at Wadi Halfa, Dongolla and Karima. The area of the State is approximately $348697 \mathrm{~km}^{2}$. The agricultural land that could be irrigated is about 1.337.451 feddans (41.667ha). The climate in the state characterized as desert (hyper-arid), typical continental, with two seasons, a hot summer from April to September and cold winter from October to March. The highest mean maximum temperature recorded is $43.1^{\circ} \mathrm{C}$ in Dongolla, while the absolute maximum is $49^{\circ} \mathrm{C}$ in Wadi Halfa. The mean minimum recorded temperature $8.3^{\circ} \mathrm{C}$ and absolute minimum is $1^{\circ} \mathrm{C}$ both recorded in Wadi Halfa. The relative humidity is low, the highest evaporation recorded in May and the lowest in January; the maximum duration of sunshine is 11.9 hours in June and the lowest duration is 9.8 hours in December and the highest vapor pressure occurs in August and the lowest occur in February. ${ }^{12}$ The average total annual rainfalls are 3,18 and $37.7 \mathrm{~mm}$ in Wadi Halfa, Dongolla and Karima respectively. Rainfall is very low falling in August that reflected in limited rain fed agriculture as well as shallow ground water. The rain increases from north to south. Table 1 shows the means of temperature and wind speed in the study area. 
Table I Monthly mean of temperature and wind speed in the selected months from karima station (2000-20I9)

\begin{tabular}{|c|c|c|c|c|c|c|c|c|c|}
\hline \multirow{3}{*}{ Years } & \multicolumn{3}{|l|}{ April } & \multicolumn{3}{|l|}{ August } & \multicolumn{3}{|c|}{ December } \\
\hline & \multirow{2}{*}{$\begin{array}{l}\text { Mean } \\
\text { Temp. }^{\circ} \mathbf{C}\end{array}$} & \multicolumn{2}{|l|}{ Wind } & \multirow{2}{*}{$\begin{array}{l}\text { Mean } \\
\text { Temp. }{ }^{\circ} \mathbf{C}\end{array}$} & \multicolumn{2}{|l|}{ Wind } & \multirow{2}{*}{$\begin{array}{l}\text { Mean } \\
\text { Temp. }^{\circ} \mathbf{C}\end{array}$} & \multicolumn{2}{|l|}{ Wind } \\
\hline & & Speed (knots) & Dir. & & Speed (knots) & Dir. & & Speed (knots) & Dir. \\
\hline 2000 & 31.8 & 6 & $N$ & 36.36 & 6 & $N$ & 20.8 & 5 & $\mathrm{~N}$ \\
\hline 2001 & 31.2 & 7 & $\mathrm{~N}$ & 36.5 & 5 & $N$ & 22.7 & 6 & $\mathrm{~N}$ \\
\hline 2002 & 31.3 & 8 & NE & 36 & 6 & SW & 21.45 & 8 & NNE \\
\hline 2003 & 32.25 & 7 & NNE & 32.85 & 5 & SW & 24.35 & 8 & $\mathrm{~N}$ \\
\hline 2004 & 31 & 7 & $\mathrm{~N}$ & 36.1 & 5 & NW & 21.6 & 8 & NNE \\
\hline 2005 & 31.75 & 8 & NE & 36.2 & 6 & NW & 25.15 & 8 & $\mathrm{~N}$ \\
\hline 2006 & 29.2 & 4 & NNE & 35.75 & 4 & SW & 18.6 & 6 & $\mathrm{~N}$ \\
\hline 2007 & 31.05 & 5 & $\mathrm{~N}$ & 34.7 & 5 & SW & 23.3 & 5 & $\mathrm{~N}$ \\
\hline 2008 & 32.75 & 6 & $N$ & 36.7 & 4 & SW & 23.75 & 5 & $\mathrm{~N}$ \\
\hline 2009 & 33.1 & 4 & NNE & 35.7 & 3 & NW & 21.6 & 4 & $\mathrm{~N}$ \\
\hline 2010 & 31.75 & 5 & NE & 36.55 & 3 & SW & 23.95 & 6 & $\mathrm{~N}$ \\
\hline 2011 & 29.85 & 9 & $N$ & 36.6 & 7 & $N$ & 22.6 & 5 & $\mathrm{~N}$ \\
\hline 2012 & 31.05 & 6 & $N$ & 35.85 & 5 & SW & 22.15 & 6 & $\mathrm{~N}$ \\
\hline 2013 & 29.75 & 7 & $N$ & 33.6 & 5 & SW & 21.35 & 8 & $\mathrm{~N}$ \\
\hline 2014 & 31.5 & 6 & $N$ & 34.8 & 6 & $\mathrm{~S}$ & 24 & 5 & $\mathrm{~N}$ \\
\hline 2015 & 28.6 & 10 & $N$ & 37.1 & 6 & $N$ & 24.5 & 8 & $\mathrm{~N}$ \\
\hline 2016 & 19.75 & 5 & $\mathrm{~N}$ & 36.45 & 5 & $S$ & 19.25 & 7 & $\mathrm{~N}$ \\
\hline 2017 & 31.65 & 8 & $N$ & 36.95 & 6 & $\mathrm{~S}$ & 25.2 & 7 & $N$ \\
\hline 2018 & 30.65 & 7 & $N$ & 34.95 & 6 & $\mathrm{~S}$ & 20.85 & 7 & $\mathrm{~N}$ \\
\hline 2019 & 30.1 & 7 & $N$ & 33.75 & 7 & $S$ & 22.15 & 7 & $\mathrm{~N}$ \\
\hline Min. & 19.8 & 4 & & 32.85 & 3 & & 18.6 & 4 & \\
\hline Max. & 33.1 & 10 & & 37.1 & 7 & & 25.2 & 8 & \\
\hline Mean & 30.5 & 6.6 & & 35.7 & 5.25 & & 22.5 & 6.45 & \\
\hline STD & 2.8 & 1.6 & & 1.2 & I.I & & 1.8 & 1.3 & \\
\hline CV (\%) & 9.1 & 23.8 & & 3.3 & 21.3 & & 8.2 & 20.4 & \\
\hline
\end{tabular}

Source: Sudan Meteorological Authority (SMA)

\section{Materials, methods and statistical analysis}

Mean monthly and daily climatic data dating back to (2001 and 2011) were obtained from the Karima meteorological station. The selected climatic data were mean monthly and daily of wind velocity, air temperature and wind direction. The meteorological data of three months were selected to represent three different climatic seasons namely: April for summer, August for autumn and December for winter. Wind speed and air temperature were subjected to some computation namely; minimum, maximum values. The mean, standard deviation (STD) and coefficient variation (CV) were done by "Excel 2000". Simple regression analysis ${ }^{13}$ was made. Prevailing winds direction was calculated according to their appearance from the total reading winds direction as percentage.

\section{Results and discussion}

\section{Results}

First season (April, August and December, 2001)

Monthly and diurnal variation of wind speed and wind direction: Wind speed varied monthly and diurnal during summer (April, 2001), the mean daily wind speed (Va) ranged from 0.6 to 17 , with a mean of $7.2 \mathrm{~m} / \mathrm{s}$, a STD of 4.3 and a CV of $60 \%$. The daily mean data ranged from $5.4(3 \mathrm{hrs})$ to $8.2(24 \mathrm{hrs})$, with a mean of $7.2 \mathrm{~m} / \mathrm{s}$, a STD of 1.1 and a CV of $15.3 \%$.The prevailing wind direction decreases in the following order: $\mathrm{N}>\mathrm{NE}=\mathrm{NNE}>\mathrm{NNW}$ and had values of $47.1 \%, 12.5 \%, 12.5 \%$ and $9.6 \%$ respectively. A graphic presentation of the monthly and diurnal variation of wind speed and wind direction data is presented in (Figures 2-4), respectively. 


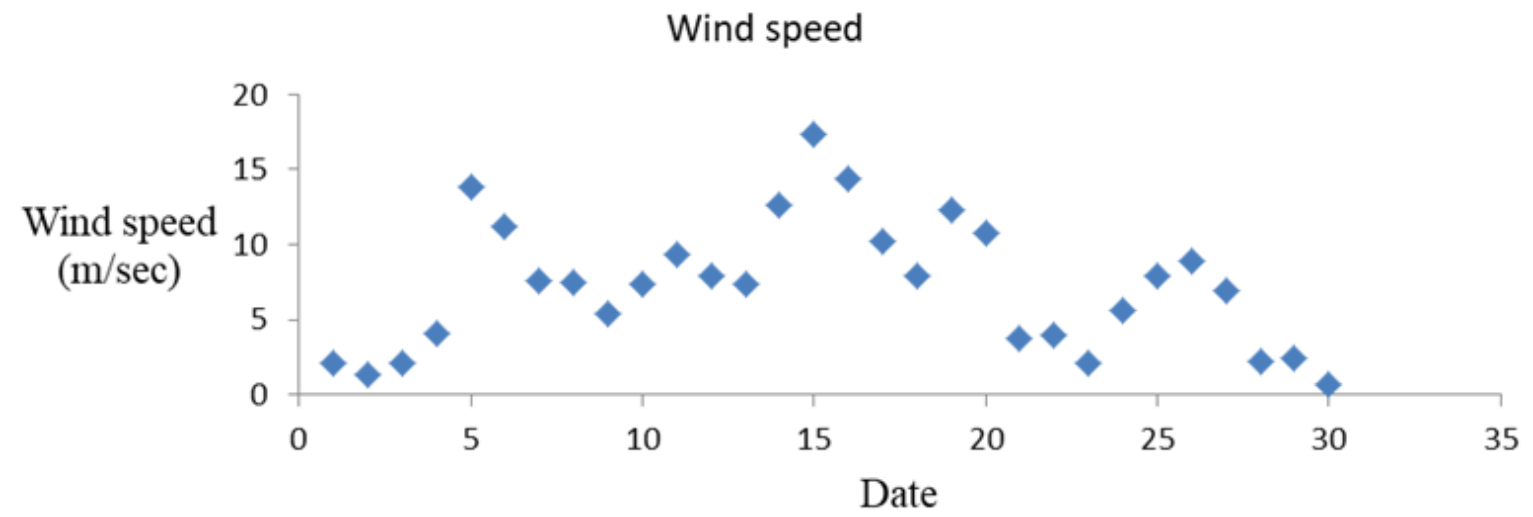

Figure 2 Monthly variation of wind speed in Apr. 200I.

\section{Wind speed}

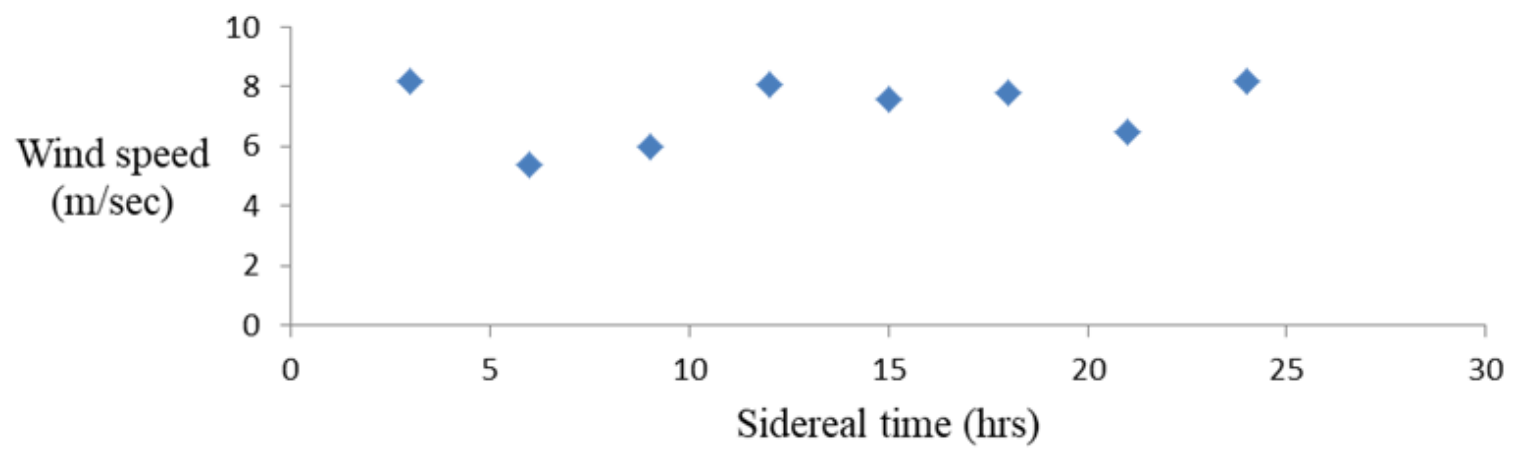

Figure 3 Diurnal variation of wind speed in Apr. 200I.

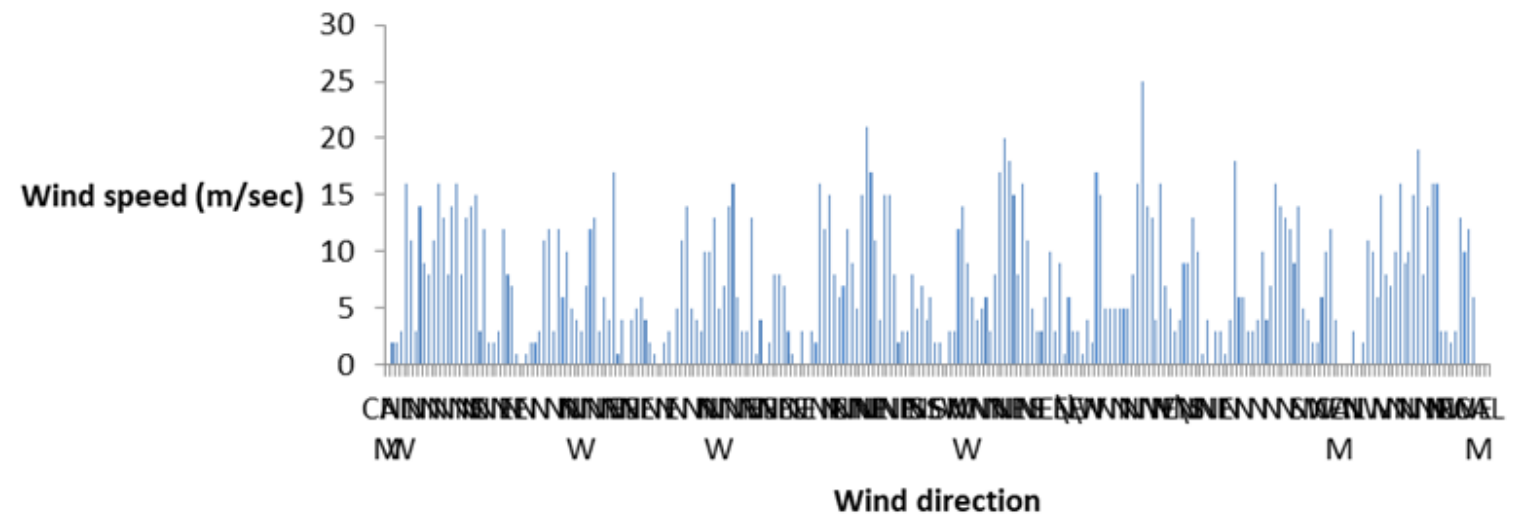

Figure 4 Wind direction in Apr. 200I.

Figures 5-7, Patterns of the monthly and diurnal variation of wind speed and direction in autumn (August, 2001). The mean daily wind speed (Va) ranged from 1.5 to 13 , with a mean of $4.8 \mathrm{~m} / \mathrm{s}$, a STD of 2.8 and a $\mathrm{CV}$ of $58.3 \%$. The daily mean data ranged from 3.1 (21 hrs) to 6.3 (3hrs), with a mean of $4.8 \mathrm{~m} / \mathrm{s}$, a STD of 0.9 and a CV of $18.8 \%$. The prevailing wind direction decreases in the following order: $\mathrm{N}>\mathrm{SW}>\mathrm{S}>\mathrm{NNW}$ accounted about $19.4 \%, 17.3 \%, 12.1 \%$ and $7.7 \%$, respectively.

In winter (December, 2001), the mean daily wind speed (Va) ranged from 2.1 to 11 , with a mean of $6.1 \mathrm{~m} / \mathrm{s}$, a STD of 2.3 and a CV of $38 \%$. The daily mean data ranged from 3.9 (6 hrs) to 8.6 (24hrs), with a mean of $6.1 \mathrm{~m} / \mathrm{s}$, a STD of 1.5 and a CV of $24 \%$. The prevailing wind direction decreases in the following order: $\mathrm{N}>\mathrm{NNE}>\mathrm{NE}>\mathrm{NNW}$ with values of $39.9 \%, 21.3 \%, 16.5 \%$ and $14.9 \%$ respectively. Monthly and diurnal variation of wind speed and wind direction data is presented in Figures 8-10. The results showed that the wind speed varied widely during each month and day even within the same climatic season. The trends of diurnal variation of wind speed in summer month were nearly similar to those in autumn. In the three different climatic seasons, the variation due to diurnal approximately was equal with meager differences. The variation of diurnal was much lower than the monthly due to the higher monthly variability of wind speed. The monthly variability of winds in different climatic seasons decreased in the following order: summer $>$ autumn $>$ winter. 


\section{Wind speed}

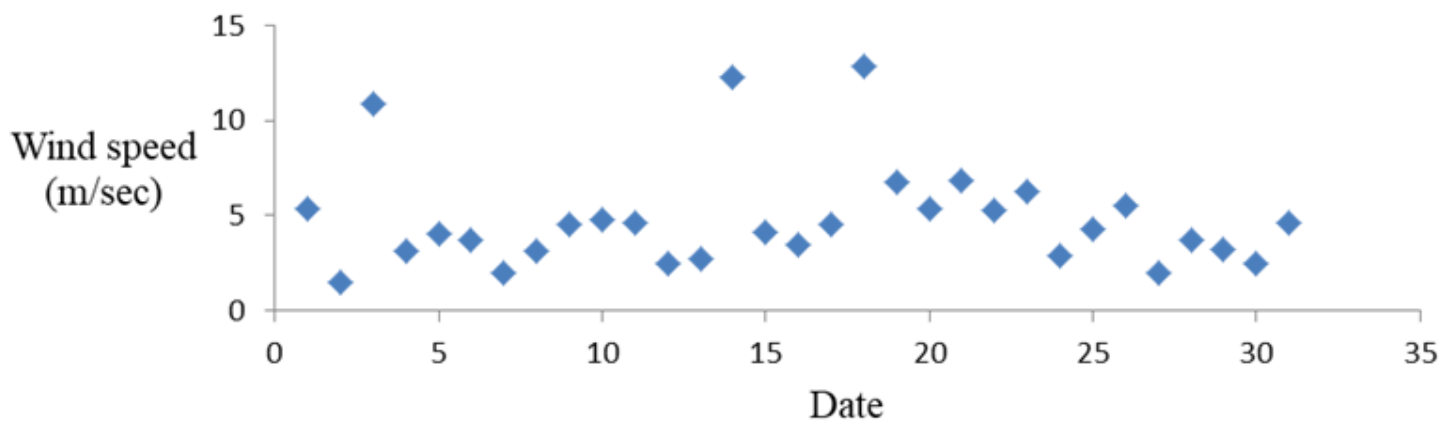

Figure 5 Monthly variation of wind speed in Aug. 200 I.

\section{Wind speed}

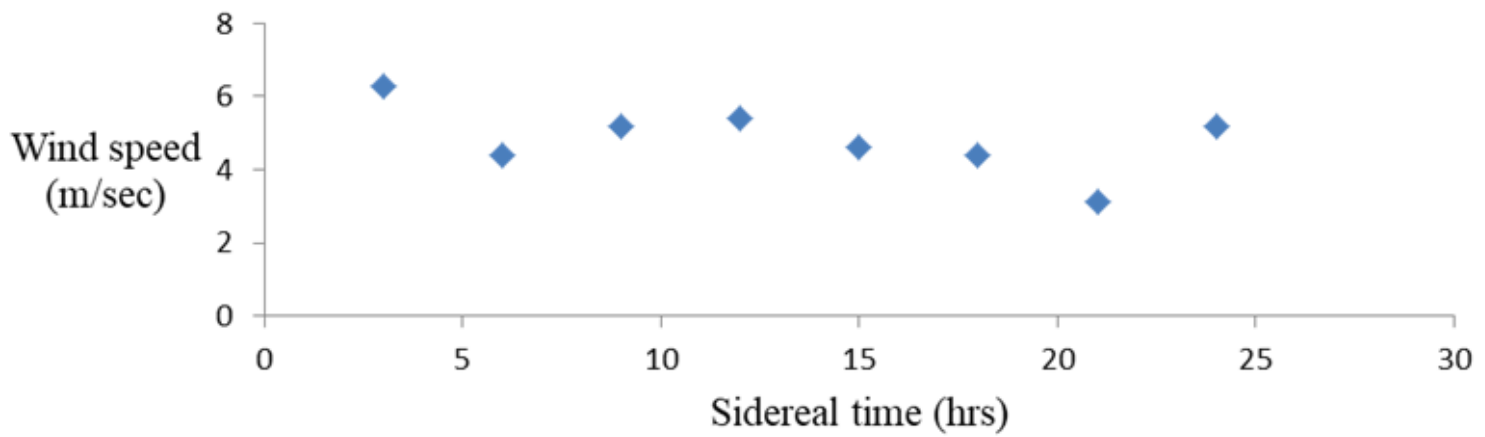

Figure 6 Diurnal variation of wind speed in Aug. 200I.

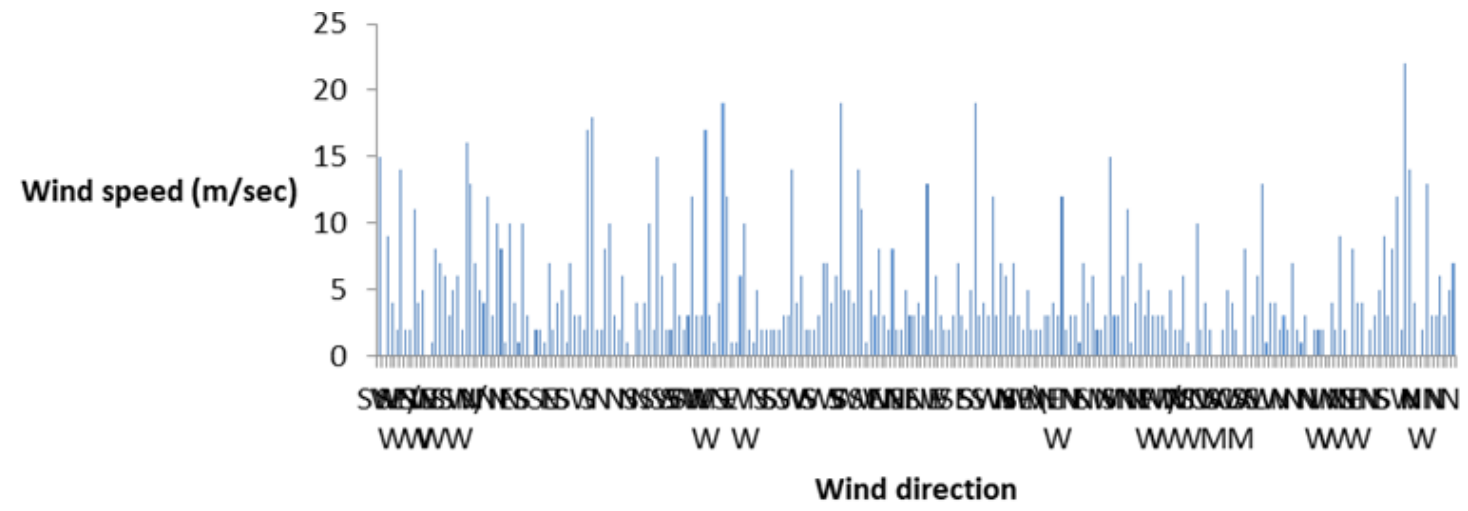

Figure 7 Wind direction in Aug. 200I.

Wind speed

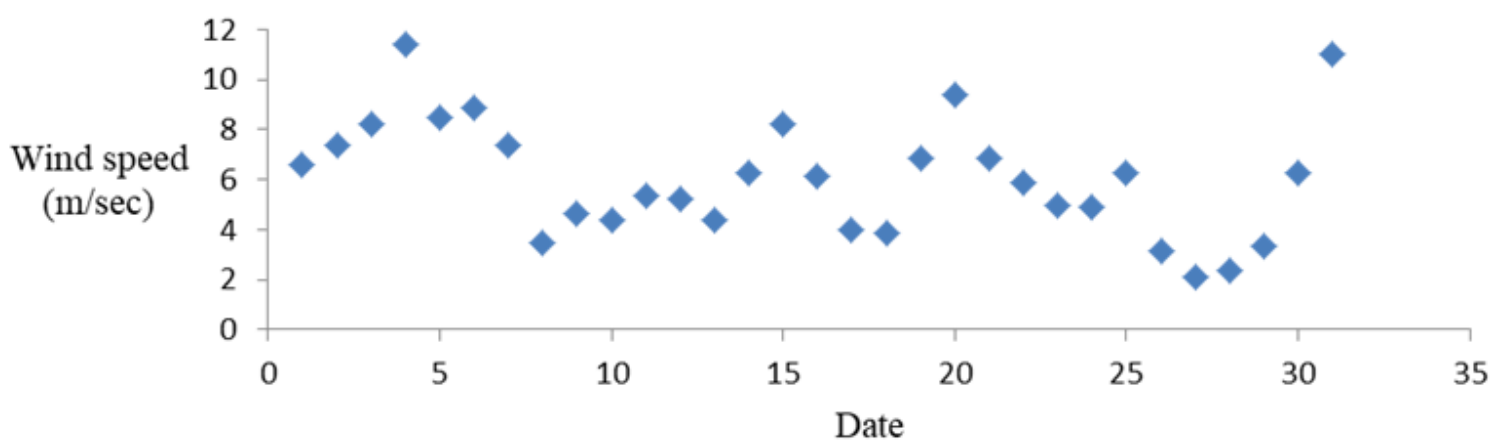

Figure 8 Monthly variation of wind speed in Dec. 200I. 


\section{Wind speed}

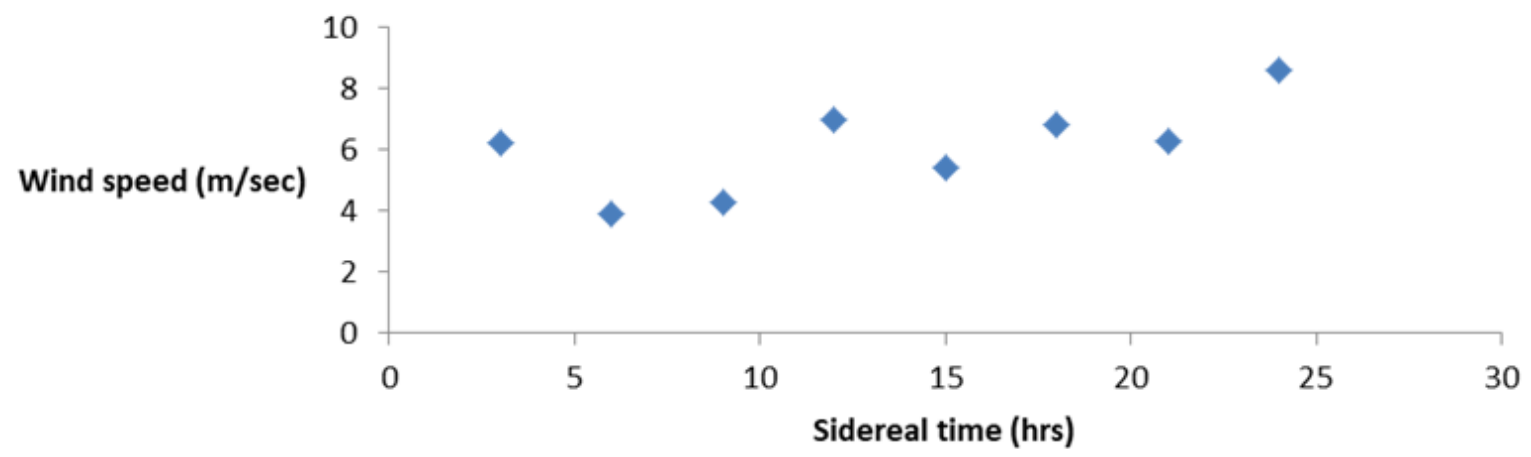

Figure 9 Diurnal variation of wind speed in Dec. 200I.

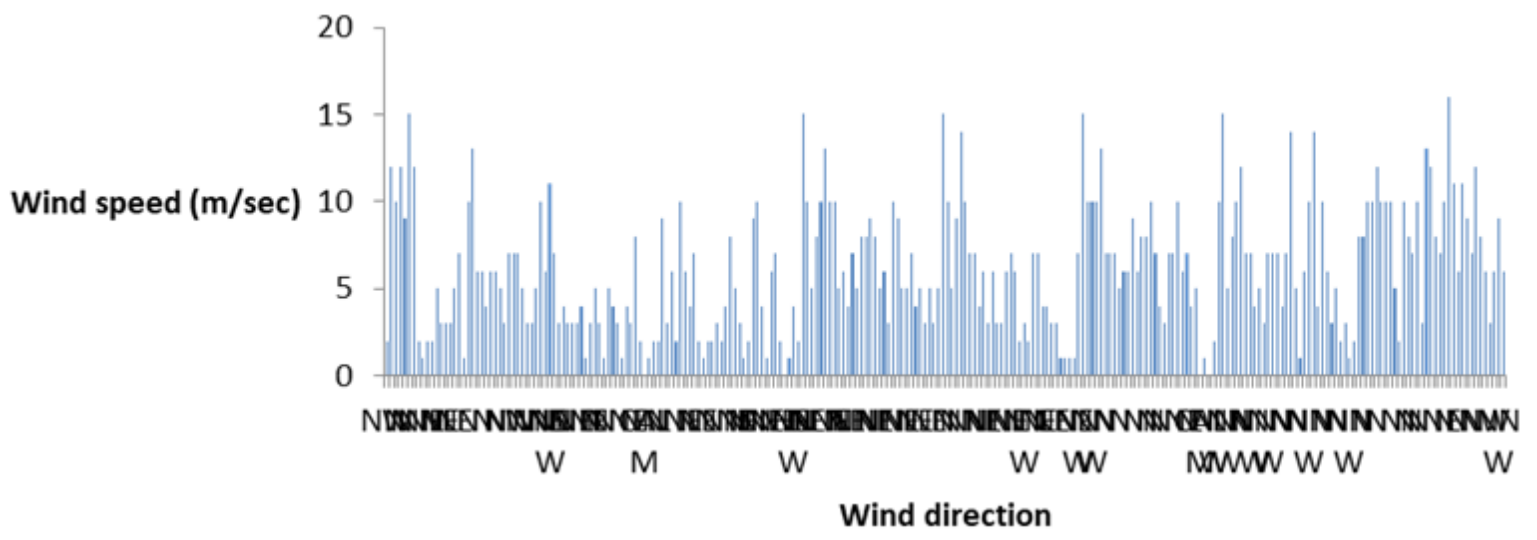

Figure I0 Wind direction in Dec. 200I.

Correlation between air temperature and wind speed in the first season: In the three climatic seasons Apr., Aug. and Dec, the mean daily air temperature ranged from 23.4 to 35.3 with a mean of $31.2^{\circ}$ C, a STD of 2.9 and a CV of $9.5 \%$; from 33.3 to 38.8 with a mean of $36.5^{\circ} \mathrm{C}$, a STD of 1.4 and a CV of $3.8 \%$; and from 17.4 to 26.4 with a mean of $21.3^{\circ} \mathrm{C}$, a STD of 2.3 and a CV of $10.6 \%$ respectively. The monthly variability of the air temperature decreased in the following order: winter $>$ summer $>$ autumn. Simple regression analysis between wind speed and air temperature in Aug. showed a significant difference $(\mathrm{p}<0.05, \mathrm{R}=0.362)$ cubic, decreases in wind speed with increases in air temperature. Air temperature accounted for about $15.1 \%$ of the variability of the wind speed. In Dec. the correlation gave inversely proportional with a highly significant relationship $(\mathrm{p}<0.01, \mathrm{R}=0.488)$. Air temperature accounted for about $23.8 \%$ of the variability of the wind speed. However summer data showed no significant correlation. Regression analysis between wind speed and air temperature data is presented in Table 2 .

Table 2 Equations of the trend lines showing the relationship between air temperature and wind speed during first season

\begin{tabular}{llllllll}
\hline Months & Type of equation & $\mathbf{a}$ & $\mathbf{b}$ & $\mathbf{c}$ & $\mathbf{d}$ & $\mathbf{R}$ & $\mathbf{R}^{2}$ \\
\hline April & Cubic & -0.0143 & 1.2348 & -35.305 & 342.09 & 0.204 & 0.0415 \\
August & Cubic & 0.1142 & -12.193 & 432.44 & -5090.2 & 0.389 & 0.151 \\
December & Cubic & 0.0003 & -0.0358 & 0.6618 & 6.2975 & 0.488 & 0.2378 \\
\hline
\end{tabular}

*Cubic: $Y=a x 3+b x 2+c x+d . R(0.05)=0.3620 ; R(0.0 I)=0.4640 ; R(0.00 I)=0.57 I 4$

Second season (April, August and December, 2011)

Monthly and diurnal variation of wind speed and wind direction: Wind speed varied monthly and diurnal during summer (April, 2011), the mean daily wind speed ( $\mathrm{Va}$ ) ranged from 0.4 to 18 , with a mean of $8.7 \mathrm{~m} / \mathrm{s}$, a STD of 4.8 and a CV of $55.2 \%$. The daily mean data ranged from $6.8(21 \mathrm{hrs})$ to $11(12 \mathrm{hrs})$, with a mean of $8.7 \mathrm{~m} / \mathrm{s}$, a STD of 1.5 and a $\mathrm{CV}$ of $17.2 \%$. The prevailing wind direction decreases in the following order: $\mathrm{N}>\mathrm{NE}>\mathrm{NNE}>\mathrm{NNW}$ accounted for about $33.3 \%$, $18.8 \%, 13.3 \%$ and $8.3 \%$ respectively. A graphic presentation of the monthly and diurnal variation of wind speed and wind direction data is presented in (Figures 11-13), respectively.

Figures 14-16 show the patterns of the monthly and diurnal variation of wind speed and direction in autumn (August, 2011). The mean daily wind speed (Va) ranged from 0 to 11 , with a mean of $5.5 \mathrm{~m} / \mathrm{s}$, a STD of 3.3 and a CV of $60 \%$. The daily mean data ranged from $3.4(21 \mathrm{hrs})$ to $7.8(24 \mathrm{hrs})$, with a mean of $5.5 \mathrm{~m} / \mathrm{s}$, a STD of 1.5 and a $\mathrm{CV}$ of $27.3 \%$. The prevailing wind direction decreases in the following order: $\mathrm{N}>\mathrm{NE}>\mathrm{NNW}>\mathrm{S}$ and accounted for about $14.9 \%$, $11.7 \%, 6.8 \%$ and $6.4 \%$, respectively. 


\section{Wind speed}

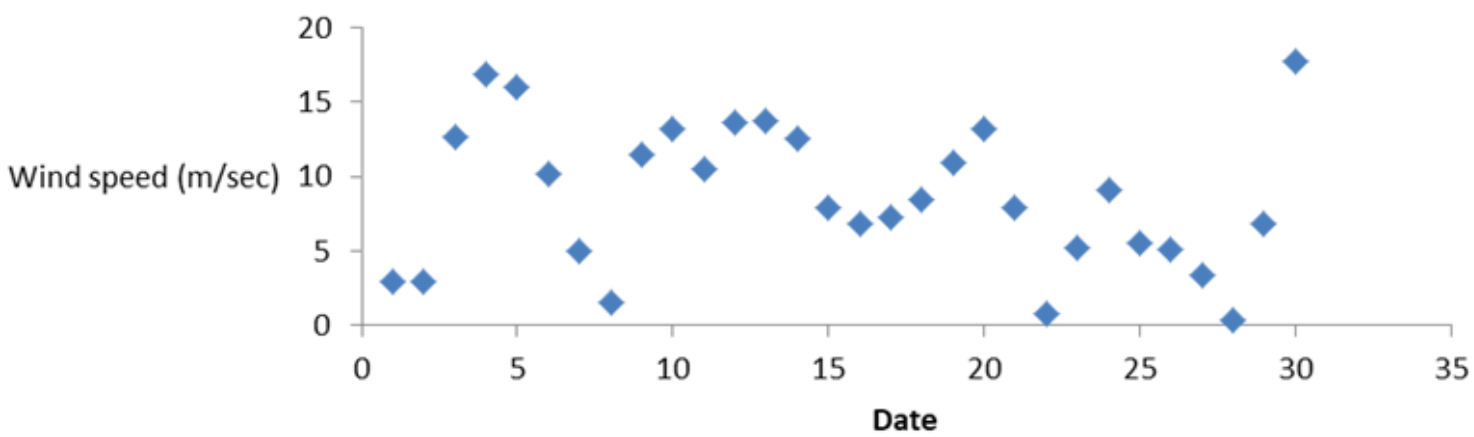

Figure I I Monthly variation of wind speed in Apr. 201 I.

wind speed

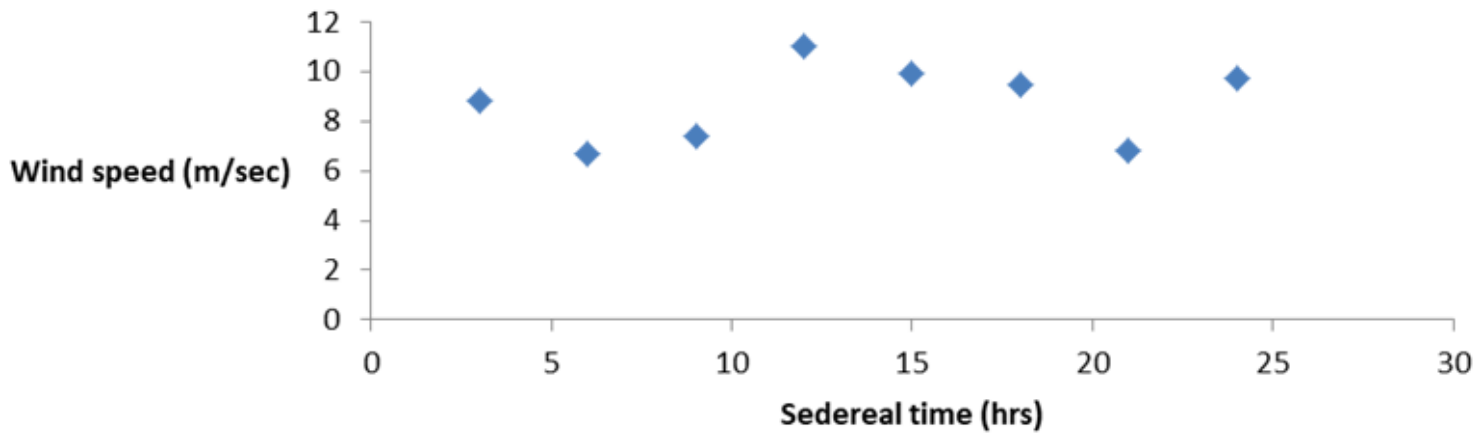

Figure I 2 Diurnal variation of wind speed in Apr. 20 I I.

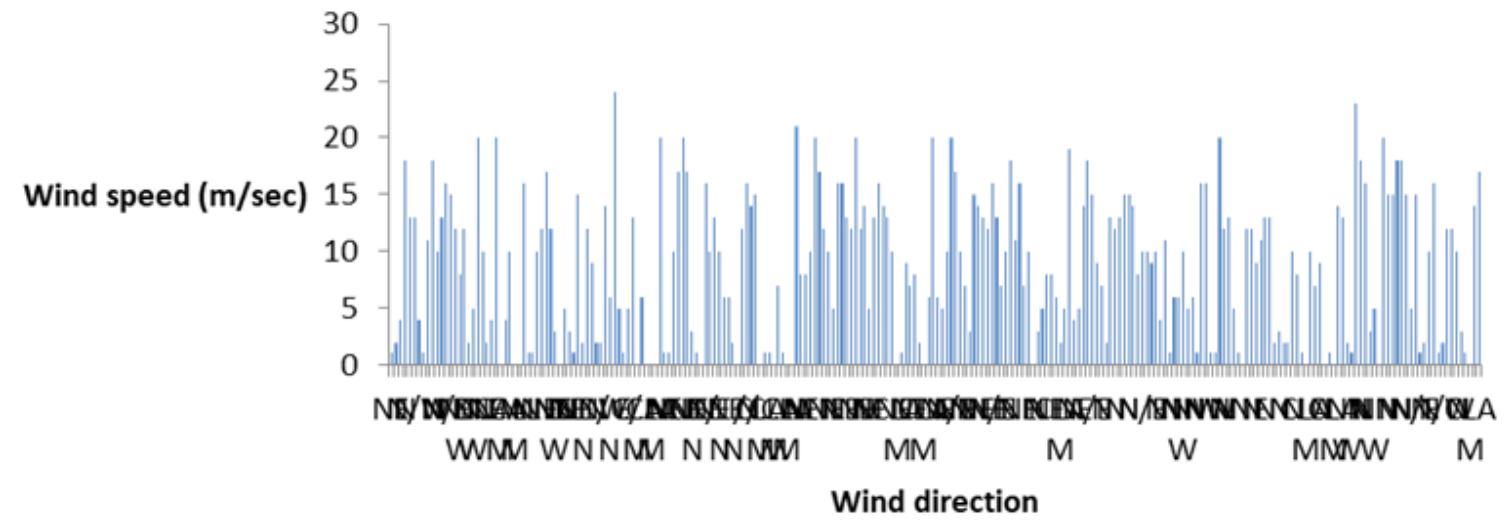

Figure I 3 Wind direction in Apr. $201 \mathrm{I}$.

\section{Wind speed}

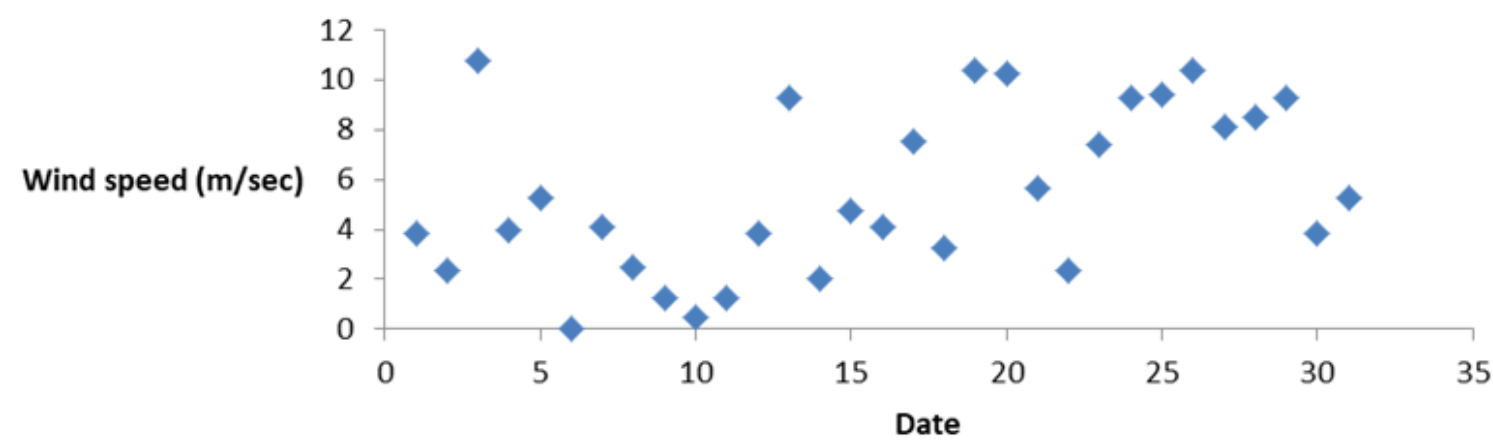

Figure I 4 Monthly variation of wind speed in Aug. 201 I. 
wind speed

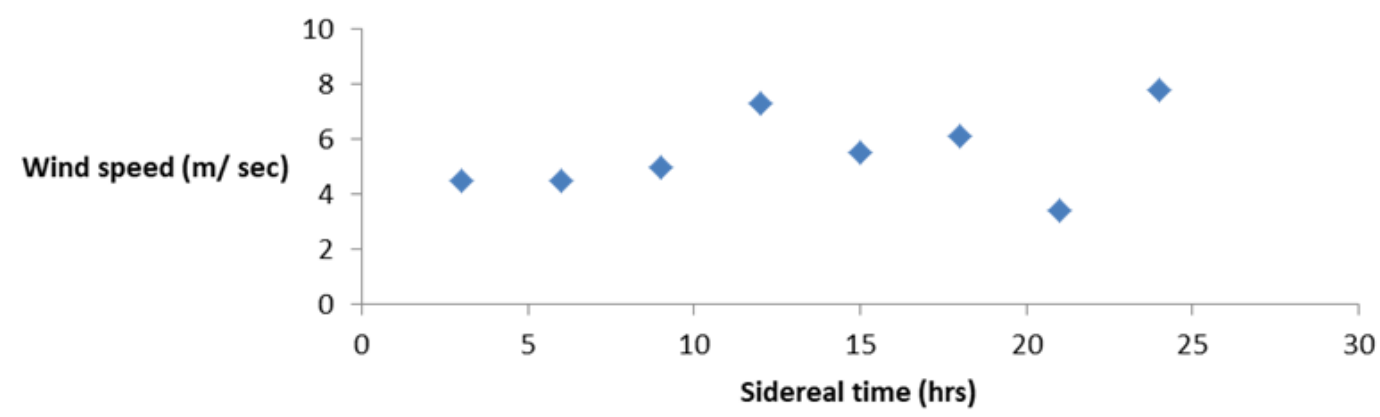

Figure 15 Diurnal variation of wind speed in Aug. 2011.

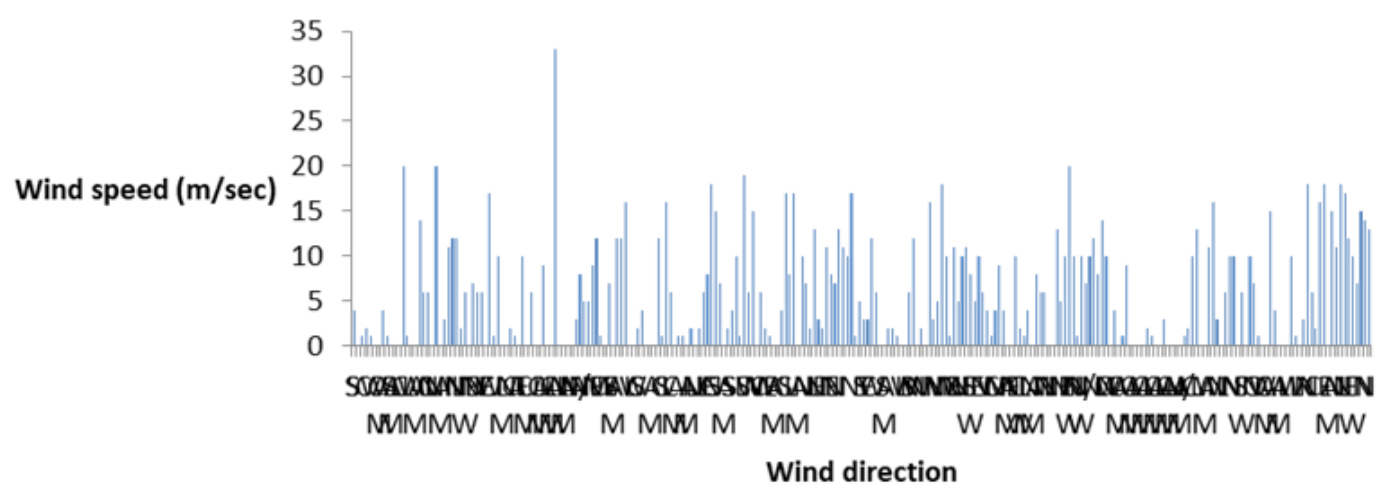

Figure 16 wind direction in Aug. $201 \mathrm{I}$.

In winter (December, 2011), the mean daily wind speed (Va) ranged from 0.3 to 12 , with a mean of $5.4 \mathrm{~m} / \mathrm{s}$, a STD of 3.1 and a CV of $57.4 \%$. The daily mean data ranged from 3.2 (6 hrs) to 7.9 (24hrs), with a mean of $5.4 \mathrm{~m} / \mathrm{s}$, a STD of 1.6 and a CV of $30 \%$. The prevailing wind direction decreases in the following order: $\mathrm{N}>\mathrm{NE}>\mathrm{NNW}>\mathrm{NNE}$ and accounted for about 44\%, 11.7\%, 9.6\% and 9.2\% respectively. Monthly and diurnal variation of wind speed and wind direction data are presented in Figures 17-19, respectively.

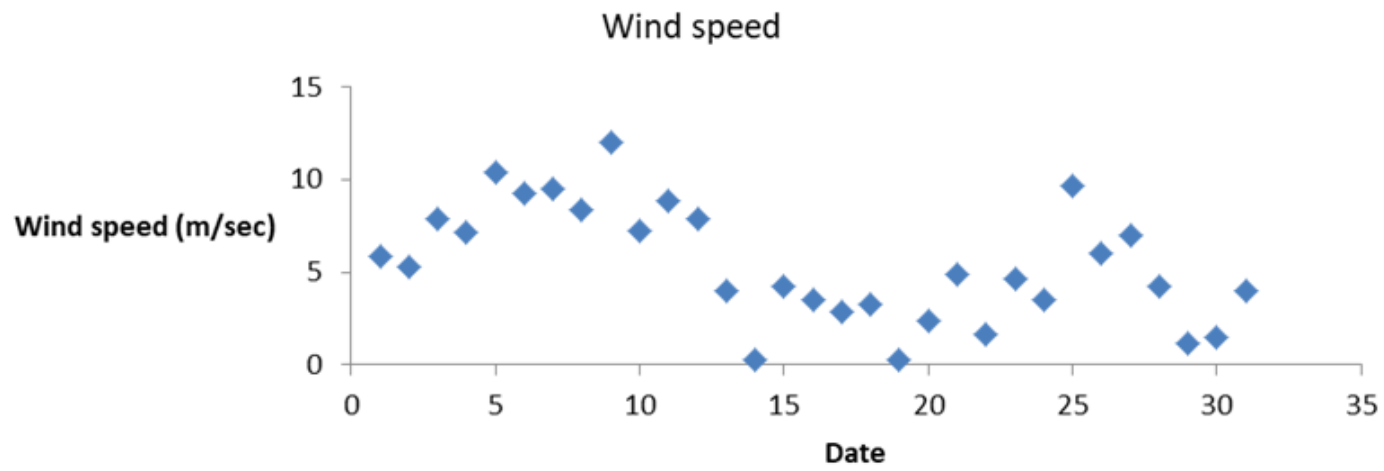

Figure 17 Monthly variation of wind speed in Dec. 20II.

wind speed

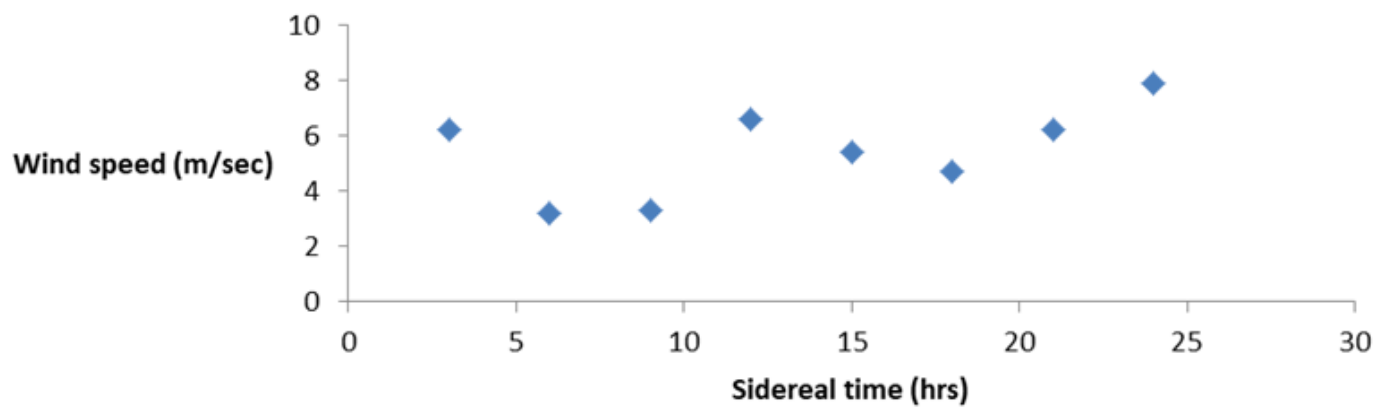

Figure 18 Diurnal variation of wind speed in Dec. $201 \mathrm{l}$.

Citation: Alzubair MAH,Abdelwahab MH. Temporal variation of wind speed and wind direction and interrelationship between air temperature and wind speed for different climatic seasons Northern State, Sudan. MOJ Eco Environ Sci. 2021;6(4):I64-173. DOI: 10.15406/mojes.202I.06.00229 


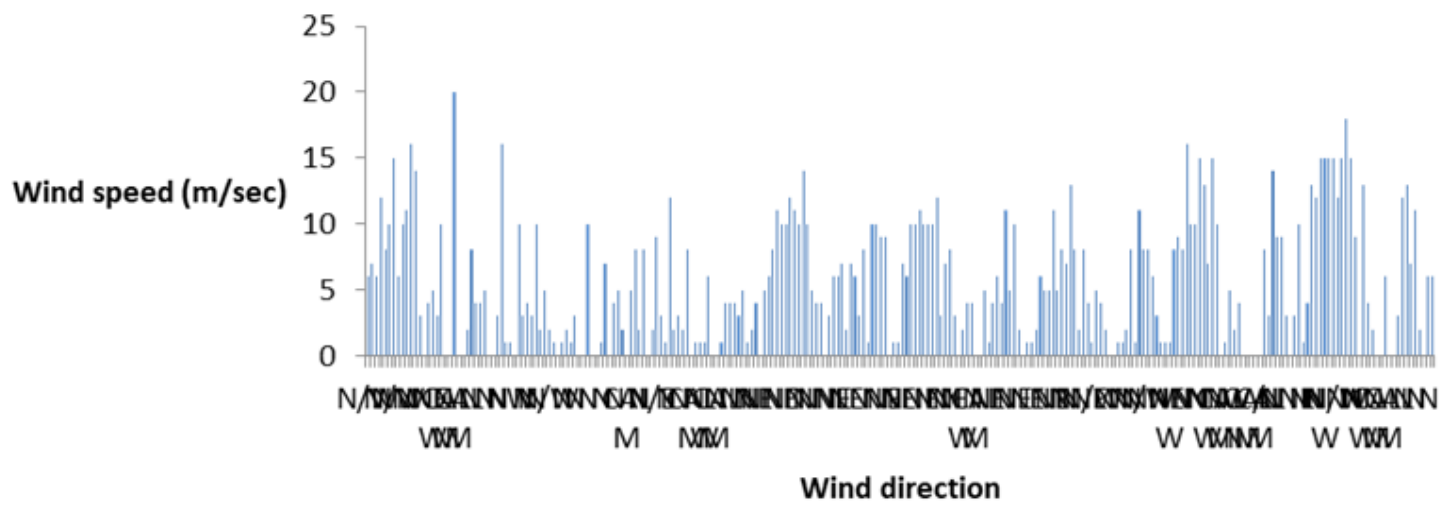

Figure 19Wind direction in Dec. 20II

The results showed that the wind speed varied widely during each month and day even within the same climatic season. The trend of diurnal variation of wind speed in summer was nearly similar to that in winter. In the three different climatic seasons the diurnal variation was much lower than the monthly due to the higher monthly variability of wind. The monthly variability of winds in different climatic seasons decreased in the following order: autumn $>$ winter $>$ summer.

Correlation between air temperature and wind speed in the second season: In the three climatic seasons Apr., Aug. and Dec. the mean daily air temperature ranged from 24.4 to 33.6 with a mean of $30^{\circ} \mathrm{C}$, a STD of 2.2 and a CV of $7.5 \%$; from 35.3 to 38.2 with a mean of $36.6^{\circ} \mathrm{C}$, a STD of 0.88 and a CV of $2.4 \%$; and from 19.7 to 26 with a mean of $22.6^{\circ} \mathrm{C}$, a STD of 1.7 and a $\mathrm{CV}$ of $7.7 \%$, respectively. The monthly variability of the air temperature decreased in the following order: winter $>$ summer $>$ autumn. Simple regression analysis between wind speed and air temperature in Aug. showed a highly significant difference $(\mathrm{p}<0.001, \mathrm{R}=0.585)$ cubic, decreases in wind speed with increases in air temperature. Air temperature accounted for about $34.2 \%$ of the variability of the wind speed. In Dec. the correlation was inversely proportional with highly significant relationship $(\mathrm{p}<0.001, \mathrm{R}=0.679)$. Air temperature accounted for about $46.2 \%$ of the variability of the wind speed. However summer data showed no significant correlation. Regression analysis between wind speed and air temperature data is presented in Table 3.

Table 3 Equations of the trend lines showing the relationship between air temperature and wind speed during second season

\begin{tabular}{llllllll}
\hline Months & Type of equation & $\mathbf{a}$ & $\mathbf{b}$ & $\mathbf{c}$ & $\mathbf{d}$ & $\mathbf{R}$ & $\mathbf{R}^{2}$ \\
\hline April & Cubic & 0.0498 & -4.5617 & 138.33 & -1380.6 & 0.313 & 0.0982 \\
August & Cubic & -0.6039 & 66.635 & -2450.7 & 30046 & 0.585 & 0.342 \\
December & Cubic & 0.2205 & -15.335 & 353.1 & -2686.8 & 0.679 & 0.4616 \\
\hline
\end{tabular}

*Cubic: $Y=a \times 3+b \times 2+c x+d . R(0.05)=0.3296 ; R(0.0 I)=0.4243 ; R(0.00 I)=0.5259$

\section{Discussion}

Wind is the horizontal movement of air in response to differences in pressure. Winds are the means by which the atmosphere attempts to balance the uneven distribution of pressure over Earth's surface. The winds are slowed down by the earth's surface roughness and obstacles. In two seasons, the results showed that the wind speed varied widely during each selected month and day even within the same climatic seasons. Similarly the monthly wind speed variability for the seasons Apr., Aug. and Dec. was much higher than that of diurnal wind speed and air temperature. This fact was attributed to the higher monthly variability of wind speed and uneven distribution of pressure over the state. Moreover the majority of the Northern state was bare, with few windbreaks beside the prevalent climatic conditions including high temperature, very low and erratic rainfalls conducive to the high variability of winds. This finding agrees with previous finding of Abuzied ${ }^{12}$ and Abdelwahab. ${ }^{14}$ Summer and winter results for two seasons showed that the prevailing wind direction was northerly rotated among N, NE, NNE and NNW. This fact may be attributed to the effect of the Trade Winds. These winds blow predominantly from the northeast in the Northern Hemisphere and from the southeast in the Southern Hemisphere. This result agrees with prevailing global wind directions. ${ }^{15,16}$ In autumn (summer precipitation), there was a high contribution of winds blowing from northern direction in two seasons. The S and SW (southerly winds) also contributed. These winds caused rainfall in vast area of the country, ultimately reaching the state without, or rare clouds that may resulted in $0 \mathrm{~mm}$ rainfall.

Temperature and pressure are directly proportional to each other. This means that as the temperature decreases, the pressure also decreases, and vice versa. A hot surface heats the air above it and the air expands, lowering the air pressure and its density. The resulting horizontal pressure gradient accelerates the air from high to low pressure, creating wind. The relationship between wind speed and pressure are co-dependent with temperature. ${ }^{4}$

In the first and second seasons, wind speed-air temperature correlation for winter were inversely proportional with a highly significant relationship $\left(\mathrm{p}<0.01, \mathrm{R}=0.488\right.$ and $\left.\mathrm{R}^{2}=23.8 \%\right)$ and $\left(p<0.001, R=0.679\right.$ and $\left.R^{2}=46.2 \%\right)$, respectively.

The precipitation type in Sudan is summer precipitation. Interrelationship in autumn exhibited a significant correlation in two 
seasons $\left(\mathrm{p}<0.05, \mathrm{R}=0.362\right.$ and $\left.\mathrm{R}^{2}=15.1 \%\right)$ and $(\mathrm{p}<0.001, \mathrm{R}=0.585$ and $\left.\mathrm{R}^{2}=34.2 \%\right)$, respectively, indicating that warm summers tended to be dryer. This finding agrees with previous finding. ${ }^{17}$ However summer data (Apr.) showed no significant correlation in two seasons. This result may be attributed to the effect of low air temperature variability compared to that recorded in winter season.

\section{Conclusion and recommendations}

The results showed that the wind speed varied widely in frequency and direction during each month and day even within the same climatic season. In the two seasons the diurnal variation for different climatic seasons Apr., Aug. and Dec. was much lower than the monthly, due to the higher monthly variability of wind speed. In general, the results showed that the prevailing wind direction was north.

Significant, negative and cubic wind speed-temperature correlations in the two seasons for Aug. and Dec. were found. The results showed that regression technique can be used effectively to show the relationship between climate variables. Thus, it is recommended to recarried out periodically. Due to the location of the state in the hyper-arid and arid zone beside prevalent harsh climatic conditions including high temperature, low and erratic rainfalls, these climatic conditions are highly conducive to wind erosion. So there is urgent need to establish shelterbelts to reduce wind erosion. Little quantitative analysis meteorological data is available. So there is urgent need to do serious work in this field, besides establishing new meteorological stations to give a good cover for the state.

Due to limitations of the data set, only two years of data were used for the analysis. Since some other parameters influence the winds variability and wind speed- air temperature correlation were not investigated. In spite of limitation of the data obtained results are good. So more studies should be conducted with a large data set. Climatic conditions in the state are suitable to generate solar radiation and wind energy safely and friendly to the environment.

\section{Acknowledgments}

None.

\section{Funding}

None.

\section{Conflicts of interest}

All author listed here declare no conflict of interest exists.

\section{References}

1. Carlson RE. Heat stress, plant-available soil moisture, and corn yield in Iowa: A short-and long-term view. Journal of Production Agriculture. 1990;3:293-297.
2. Madden RA, Williams J. The correlation between temperature and precipitation in the United States and Europe. Monthly Weather Review. 1978;106:142-147.

3. Trenberth KE, Shea DJ. Relationship between precipitation and surface temperature. Geophysical Research Letters. 2005.

4. Powell MD, Reinhold TA. New scales for the destructive potential of tropical storms. Proceedings of the 11th American Conference on Wind Engineering, June 22-26, San Juan, Puerto Rico; 2009:1-10.

5. Valsson S, Baharat A. Impact of air temperature on relative humidity - a study. Architure- time space \& people. 2011:38-41.

6. Kosuke Kittaka, Hiroshi Miyazaki. Relationship between wind direction and air temperature in the Osaka center city determined by using fixed point observation. Journal of Heat Island Institute International. 2014.

7. Abdelwahab MH, Mustafa MA. Monthly and diurnal variation of wind speed and direction and wind erosivity in the River Nile State, Sudan. The International Journal of Environmental and Water. 2015;4(4):1-10.

8. Adam HS, Abdalla HA. The climate of the dry lands in Sudan. In: Mustafa MA, Mahdi AA, editors. Proceedings of the National symposium of sustainable use of the dry lands in Sudan. Al Sharga Hall, 17-18 June 2008, Publ. by UNESCO Chair of Desertification, Sudan: University of Khartoum, Khartoum; 2008:5-26.

9. El Gamri T, Saeed AB, Abdalla AK. Use of global sea surface temperatures in rainfall prediction in dry lands of the Sudan. Sudan J Res. 2009;1(1):114.

10. Mohamed HA, Mohamed AA. Classification of climates of Sudan using aridity indices. Sudan J Res. 2010;2(1):62-75.

11. Mohamed HA. A simple thermal Zonation of the Sudan. Sudan J Res. 2012;4(1):1-15.

12. Abuzied HM. Mapping and Assessment of Wind Erosion in Central Northern State, Sudan Ph.D. Thesis, Desertification and Desert Cultivation Studies Institute, Sudan: University of Khartoum; 2009.

13. Little TM, Jackson F. Statistical methods in agricultural research.UCD book store. Uni. California, Davis 95616. 1975.

14. Abdelwahab MH. Assessment of wind Erosion in Atbara Region, River Nile State, Sudan. Ph.D. thesis, Sudan: University of Khartoum; 2012.

15. Wagner HJ, Mathur J. Introduction to wind energy systems, green energy and technology. Springer-Verlag Berlin Heidelberg; 2013.

16. Ralph Stockman Tarr, Frank Morton McMurry, Almon Ernest Parkins. Advanced Geography Macmillan. 1909. 246 p.

17. Weining Zhao, Khalil MAK. The relationship between precipitation and temperature over the contiguous United States; 2009. 